\title{
NUMERICAL AND EXPERIMENTAL SIMULATION OF SPONTANEOUS COMBUSTION OF COAL
}

\author{
YU ZHIJIN \& WEN HU \\ Faculty of Safety Science and Engineering, Xi' an University of Science and Technology, China.
}

\begin{abstract}
In this paper, our main aims are to make up for the defects of large-scale coal spontaneous heating tests on trial methods. An unsteady-state numerical model is developed to simulate self-heating in a largescale coal spontaneous heating reactor with experimental conditions. The self-heating process of coal is reproduced successfully, and the main characteristics of nonlinear heating and windward movement of the fire source are obtained during the whole process. By comparison, the simulated and experimental results of the Tianchi coal samples show a good agreement with the temperature rise features and fire source positions. This confirms the validity of the model. Based on the model, a sensitivity analysis is constructed to investigate the influence of the external environment on coal spontaneous heating. The main contents include (1) heat dissipation surroundings; (2) air quantity; (3) air direction. The simulated conclusions contribute to optimizing the experimental parameters and obtaining the shortest spontaneous combustion period. In addition, the model is found to be of great significance for predicting the fire source temperature and position in practical coal mine conditions.

Keywords: numerical simulation, temperature rising feature, fire source position, experimental parameters, spontaneous combustion period
\end{abstract}

\section{INTRODUCTION}

Spontaneous combustion of coal is a critical mining hazard that all coal-producing countries have to face $[1,2]$. Accurate prediction of when and where the spontaneous combustion will occur is crucial to reduce the harm caused by spontaneous combustion of coal. It is well known that the oxidizing properties of coal are the essential reason for spontaneous combustion. However, in coal mines, whether or not a fire, caused by the coal's self-heating, occurs will depend on the external environment [3]. Experimental simulation is undoubtedly the most effective way to study the formation characteristics and the evolution law of coal self-heating. However, as there are extremely complex internal and external factors, a small-scale experimental method can better reveal the thermodynamics characteristics, temperature variation, and law of production for indicator gases, although it cannot monitor the position of the fire source due to passive heating or altering the external environment [4-8]. A largescale test of the spontaneous heating of coal can well simulate the field conditions and investigate the coal oxidation and exothermic features [9]. Because of this, many large-scale experiments have been proposed under actual mine conditions and used in an attempt to predict the self-heating tendencies of coals. However, because of the long experimental period, tremendous workload, for the same coal sample, it is impossible to change the conditions and repeat experiments. Therefore, establishing numerical models is crucial to study coal's spontaneous combustion process under various conditions.

Numerous models were used to research the process of the spontaneous combustion of coal in mined-out areas, coal heaps or bunkers [10,11]. Taraba et al. revealed the characteristic of fire source versus time in coal heaps by numerical simulation [12]. Yuan et al. numerically investigated the spontaneous combustion process of coal in a large-scale coal chamber and focused on the low-temperature oxidation reaction rate [13]. Some studies also discussed the influence of simulated parameters on the rising temperature feature $[14,15]$. However, 
correlative studies on the characteristics of the fire source position and its influencing factors combined with various heat dissipation conditions were not found.

Firstly, the self-heating process of broken or crushed coals in a reactor is reproduced successfully by a numerical method. Then, through the model transformation, the influence of heat dissipation conditions, air quantity, and air direction on temperature and the position of the self-igniting fire source were evaluated, and the results were thoroughly analyzed.

\section{NUMERICAL STUDY}

Before the model is established, the following assumptions are presented:

1. Coal is homogeneous and isotropic;

2. The temperature of coal and air is equal at the same location;

3. The effects of water phase change, absorption, and desorption on temperature and volume of coal are deliberately ignored;

4. When the air outflow from the preheating water layer, its temperature is identical to the water temperature at this moment.

\subsection{Mathematical model}

The mathematical model of the spontaneous combustion of coal included gas flow, mass transport and energy conservation. Here, the governing equations are established as follow [16-18].

1. Gas flow

The Darcy-Brinkman equation, which is suggested to describe the gas flow behavior for highly permeable media, can be written as Eq. (1)

$$
-\nabla p=\frac{\mu}{k} v-\mu_{e} \nabla^{2} v
$$

where $\mathrm{p}$ is the gas pressure, $\mathrm{Pa} ; \nabla$ is the Hamilton symbol; $\mathrm{v}$ is velocity, $\mathrm{m} / \mathrm{s} ; \mu$ is dynamic viscosity, $\mathrm{Pa} \cdot \mathrm{s} ; k$ is permeability, $\mathrm{m}^{2}$; and $\mu_{e}$ is effective viscosity, $\mathrm{Pa} \cdot \mathrm{s}$.

2. Mass transport

In this part, both convective and diffusive oxygen transport are considered; these are reported in Eq. (2)

$$
\varepsilon \frac{\partial c}{\partial t}+v \nabla c=D \nabla^{2} c-r(1-\varepsilon)
$$

where $\varepsilon$ is porosity; $c$ is oxygen concentration, $\mathrm{mol} / \mathrm{m}^{3} ; t$ is time, $\mathrm{s} ; D$ is the diffusion coefficient of the gas component, $\mathrm{m}^{2} / \mathrm{s} ; r$ is the oxygen-consumption rate of coal, mol/ $\left(\mathrm{m}^{3} \cdot \mathrm{s}\right)$; this is defined as the Arrhenius equation [19].

$$
r=\frac{c}{c_{0}} A \exp (-\mathrm{E} / \mathrm{RT})
$$

where $c_{0}$ is initial oxygen concentration, $\mathrm{mol} / \mathrm{m}^{3} ; A$ is the pre-exponential factor, $\mathrm{mol} /$ $\left(\mathrm{m}^{3} \cdot \mathrm{s}\right)$; $\mathrm{E}$ is the apparent activation energy with a unit of $\mathrm{kJ} / \mathrm{mol}$; $\mathrm{R}$ is the universal gas constant. 
3. Energy conservation

The equivalent energy conservation equation includes convective and conservative processes; it is formulated as Eq. (4)

$$
\left[\left(\varepsilon \rho_{\mathrm{g}} C_{\mathrm{g}}\right)+(1-\varepsilon) \rho_{\mathrm{s}} C_{s}\right] \frac{\partial T}{\partial t}+(v \nabla)\left(\rho_{\mathrm{g}} C_{\mathrm{g}} \mathrm{T}\right)=\lambda_{\mathrm{s}} \nabla^{2} T+(1-\varepsilon) r \Delta H
$$

where $\rho_{g}, \rho_{s}$ is density of gas and coal, $\mathrm{kg} / \mathrm{m}^{3} ; \rho_{g}$ can be described as $\rho_{g}=\mathrm{M} p / T \mathrm{R}, \mathrm{M}$ is the average molecular weight of the gas, $T$ is temperature of the coal, $\mathrm{K} ; C_{g}$ and $C_{s}$ represent the heat capacity of the gas and coal, $\mathrm{J} /\left(\mathrm{kg} \cdot{ }^{\circ} \mathrm{C}\right) ; T$ is temperature, ${ }^{\circ} \mathrm{C} ; \lambda_{e}=\lambda_{g} \varepsilon+\lambda_{s}(1-\varepsilon)$, $\lambda_{g}, \lambda_{s}$ is the heat conductivity coefficient of gas and coal, $\mathrm{W} /\left(\mathrm{m} \cdot{ }^{\circ} \mathrm{C}\right)$; and $\Delta H$ is heat of reaction, $\mathrm{J} / \mathrm{mol}$.

\subsection{Simulated background}

The simulated background of a large-scale experimental furnace is shown in Figure 1. The external and inner diameter of the cylindrical reactor was 100 and $60 \mathrm{~cm}$, respectively, the height of coal loading was $150-170 \mathrm{~cm}$ and the largest coal was 1.5 tons. There was a $10-20 \mathrm{~cm}$ air buffer zone on both the top and bottom of furnace, correspondingly. In this reactor, automatic temperature measurement including thermocouples arranged in eight vertical layers of seven probes, the spacing between the layers of the monitoring point was $20 \mathrm{~cm}$, the lowest layer was $5 \mathrm{~cm}$ from the bottom, and the radial spacings were 20, 40, and $60 \mathrm{~cm}$, respectively. Gas samples including $\mathrm{CO}, \mathrm{O}_{2}, \mathrm{CO}_{2}$ and $\mathrm{CH}_{4}$ were collected manually or automatically using beam tubes which were arranged in the central axis of the furnace.
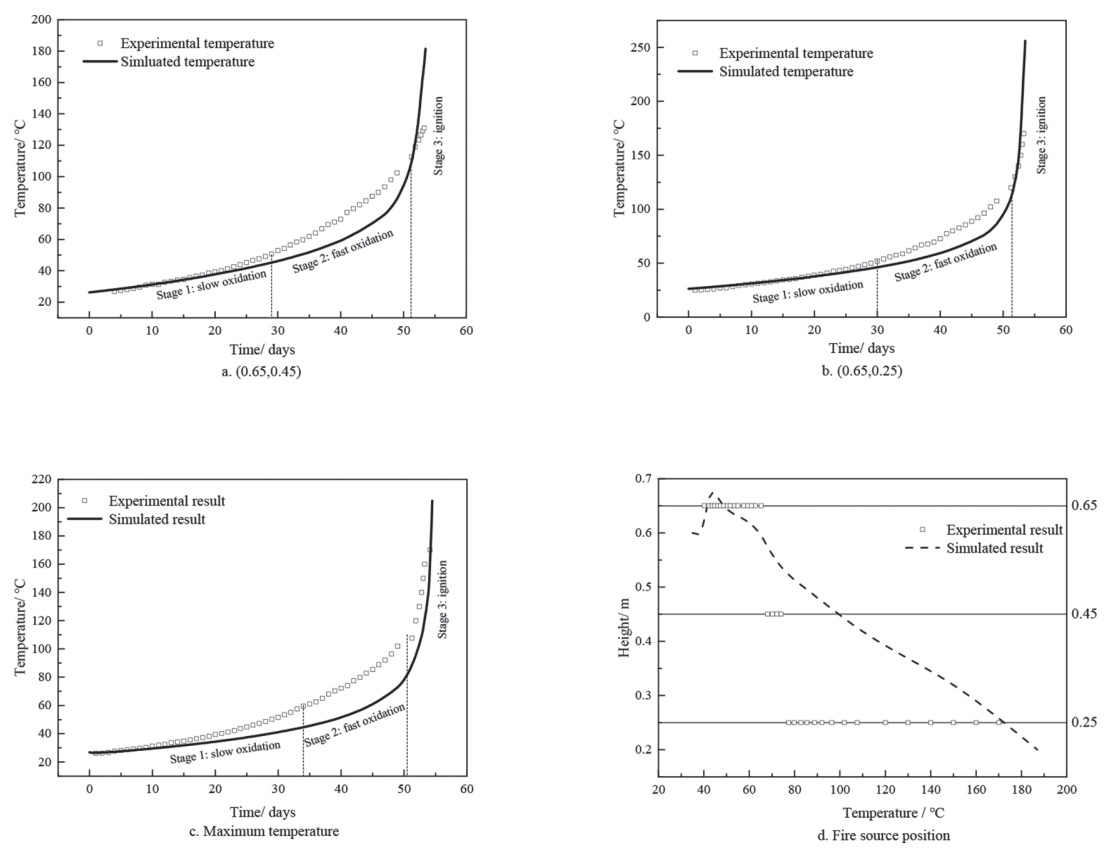

Figure 1: Large-scale coal spontaneous combustion experimental platform and its twodimensional geometric model. 
Table 1: Experimental conditions.

\begin{tabular}{llllllll}
\hline $\begin{array}{l}\text { Reference } \\
\text { particle size } \\
(\mathrm{mm})\end{array}$ & $\begin{array}{l}\text { Height } \\
(\mathrm{cm})\end{array}$ & $\begin{array}{l}\text { Mass } \\
(\mathrm{kg})\end{array}$ & $\begin{array}{l}\text { Volume } \\
\left(\mathrm{m}^{3}\right)\end{array}$ & $\begin{array}{l}\text { density } \\
\left(\mathrm{g} \mathrm{mm}^{-3}\right)\end{array}$ & $\begin{array}{l}\text { Bulk density } \\
\left(\mathrm{g} \mathrm{mm}^{-3}\right)\end{array}$ & $\begin{array}{l}\text { Initial } \\
\text { Porosity } \\
\left({ }^{\circ} \mathrm{C}\right)\end{array}$ \\
\hline 2.14 & 140 & 1415.13 & 1.58 & $1.40 \times 10^{-3}$ & $0.89 \times 10^{-3}$ & 0.36 & 26.2 \\
\hline
\end{tabular}

Table 2: Proximate analyses of the coal sample.

\begin{tabular}{lllll}
\hline Coal sample & Moisture (wt.\%) & Volatiles (wt.\%) & Fixed carbon (wt.\%) & Ash (wt.\%) \\
\hline Tianchi & 8.2 & 42.00 & 58.75 & 5.21 \\
\hline
\end{tabular}

Gas chromatography was used to analyze the gas composition and concentration. The detailed structure and process of the experimental apparatus are described in the literature [9]. The geometric model is established at the ratio of 1:1. The experimental conditions and proximate analysis of the Tianchi coal sample are shown in Table 1 and Table 2, respectively.

\subsection{Procedure for solution}

The solved parameters are obtained either from the experimental results, including porosity, oxygen-consumption rate and heat of reaction, or from the related research results $[9,20]$. The boundary conditions (Table 3 ) are set as far as possible according to the heat preserving circumstances of the experimental furnace. Then a finite element method is adopted for solving the governing equations.

Note: $Q$ is the air quantity of the inlet, with air flow moving from the bottom to the top. The initial air quantity is $0.1 \mathrm{~m}^{3} / \mathrm{h}$. However, in view of with the temperature rising, the requirement of air volume significantly increases. Therefore, to obtain the shortest spontaneous combustion period, the air quantity increased to $0.2 \mathrm{~m}^{3} / \mathrm{h}$ when the maximum temperature reached $60^{\circ} \mathrm{C}, 0.3 \mathrm{~m}^{3} / \mathrm{h}$ when the maximum temperature reaches $110^{\circ} \mathrm{C}$. Beyond $170^{\circ} \mathrm{C}$, the air quantity is fixed at $0.4 \mathrm{~m}^{3} / \mathrm{h} . T_{1}$ is the temperature of the preheating water layer. When the minimum temperature of the coal close to the water layer is below $100^{\circ} \mathrm{C}, T_{1}$ is equal to the coal temperature close to the water layer. Otherwise, $T_{1}$ is fixed at $100^{\circ} \mathrm{C}$. $h$ is the heat transfer coefficient of the wall which is $0.15 \mathrm{~W} /\left(\mathrm{m}^{2} \cdot{ }^{\circ} \mathrm{C}\right)$ in the model; $n$ represents the normal component.

Table 3: Boundary conditions of the model.

\begin{tabular}{llll}
\hline Physical field & Boundary conditions & & \\
\hline & Air inlet & Air outlet & Wall \\
\hline Flow & $Q=0.1-0.4 \mathrm{~m}^{3} / \mathrm{h}$ & $p=0$ & $-n v=0$ \\
$\mathrm{O}_{2}$ concentration & $c=9.375 \mathrm{~mol} / \mathrm{m}^{3}$ & & $-n(-D \nabla c+v c)=0$ \\
Temperature & $T=T_{1}$ & $-n\left(\lambda_{e q} \nabla T\right)=0$ & $-n\left(\lambda_{e q} \nabla T\right)=h\left(T_{1}\right.$ - T $)$ \\
\hline
\end{tabular}




\subsection{Results and validation}

The test for spontaneous heating of Tianchi coal finished when the coal temperature reached $170^{\circ} \mathrm{C}[20]$. During the experimental procedure, the central fire source zone always varied along the central axis. This is because the air flow along the central axis leads to a sufficient oxygen supply at this location. The comparison between the simulated and experimental results is shown in Figure 2.

The experimental results were compared to the simulated results in Figure $2 \mathrm{a}-\mathrm{d}$; this showed the same rule on temperature rise features at the same place in Figure 2a-c. There was an obvious nonlinear heating characteristic during the whole process of spontaneous combustion. The highest temperature reached by Tianchi coal was $170^{\circ} \mathrm{C}$ when the experiment had been underway for 54.1 days, contrasted with 53.1 days for the simulated results in Figure 2c. As is reported in Figure $2 \mathrm{a}-\mathrm{c}$, during the period when the temperature was between 50 and $100^{\circ} \mathrm{C}$, the simulated results are always lower than the measured results. The influence of moisture on heat release is neglected in the model, which is the main reason for this phenomenon [21]. Figure $2 \mathrm{~d}$ showed the variations of the maximum temperature postions, it illustrated that when the temperature of the fire source was more than $50^{\circ} \mathrm{C}$, as the temperature rises, the position of the fire source changes correspondingly, and the tendency is to move towards the wind side. The significant increase of oxygen-consumption rate at high temperature stage should be responsible for this phenomenon. Finally, combustion always takes place at the face. Moreover, as can be seen in Figure $2 d$ that there was a slight deviation in fire source positions between the experimental and the simulated results at the same temperature range. However, taking into account the distance between the adjacent measuring points $(0.25,0.45$ and $0.65 \mathrm{~cm}$ height in the reactor), which is $20 \mathrm{~cm}$ in the experimental installation, also the locations of high temperature points could only be embodied by fixed sensing points in a certain space. Therefore, it demonstrated that simulated results can accurately reflect the positions of fire source at different temperature stages.

In a word, despite the existence of the deviation, the verified numerical methods can make up for the defects of the experiment and predict the temperatures and the positions of the spontaneous fire source of coal at various temperature stages in a large-scale spontaneous heating reactor.
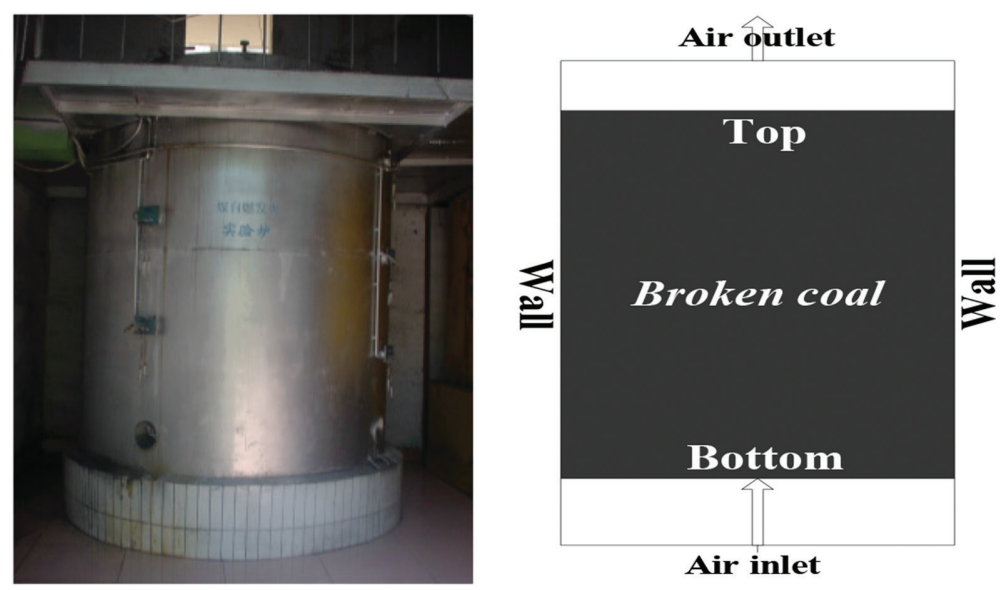

Figure 2: Comparison of simulated and experimental results. 


\section{SELF-HEATING SUSCEPTIBILITY ANALYSES}

\subsection{Effect of the conditions of heat dissipation}

The spontaneous combustion of coal is closely related to the complicated external environment. Whether the heat from low-temperature oxidation accumulates or not is primarily dependent on the heat dissipation to the surroundings [20, 22]. However, the experimental equipment only provides a closed system and results in heat dissipation only by forced ventilation. These conditions are different from the actual coal mine environment. In this section, the boundary conditions in the heat transfer equations are modified to simulate various conditions of heat dissipation. The atmospheric environment which the parameters $h$ and $T_{1}$ in Table 3 would be changed into $10 \mathrm{~W} /\left(\mathrm{m}^{2} \cdot{ }^{\circ} \mathrm{C}\right)$ for $h$ and fixed temperature $20^{\circ} \mathrm{C}$ for $T_{1}$ is used to contrast with the experimental conditions when the highest temperature reached 100, 200 and $300{ }^{\circ} \mathrm{C}$; the respective temperature profiles are presented in Figure 3.

Figure 3 indicated that the conditions of heat dissipation were a significant factor in fire source positions. At the same temperature period, with a stronger heat dissipation capacity, the center fire source is formed at a location further from the air surface under the same air quantity, and the high temperature zone becomes more concentrated. In worse heat dissipation conditions, another distinct feature is that the temperature gradient is reduced and the high temperature zone is amplified due to a radial spread occurring simultaneously. Both the thermal conduction characteristics of coal and the buoyancy effect are responsible for the above-mentioned phenomenon. The rising coal temperature characteristics in experimental conditions and at atmospheric temperature are shown in Figure 4.

Figure 4 showed that, in the atmospheric environment, the spontaneous combustion period of coal was clearly extended. But a similar heating rate of coal will be obtained in both the atmospheric environment and the experimental conditions when the maximum temperature exceeds $100^{\circ} \mathrm{C}$. The numerical and experimental results proposed a common rule that there
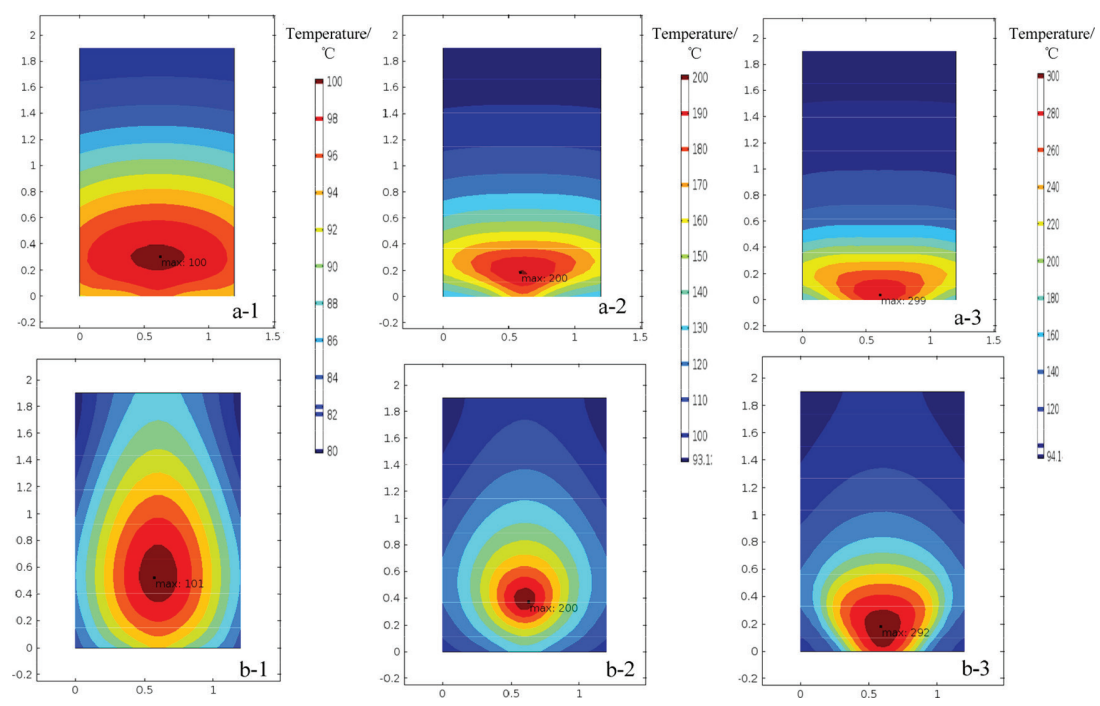

Figure 3: The temperature profile in various heat dissipation conditions; (a) under experimental conditions and (b) under atmospheric temperature. 


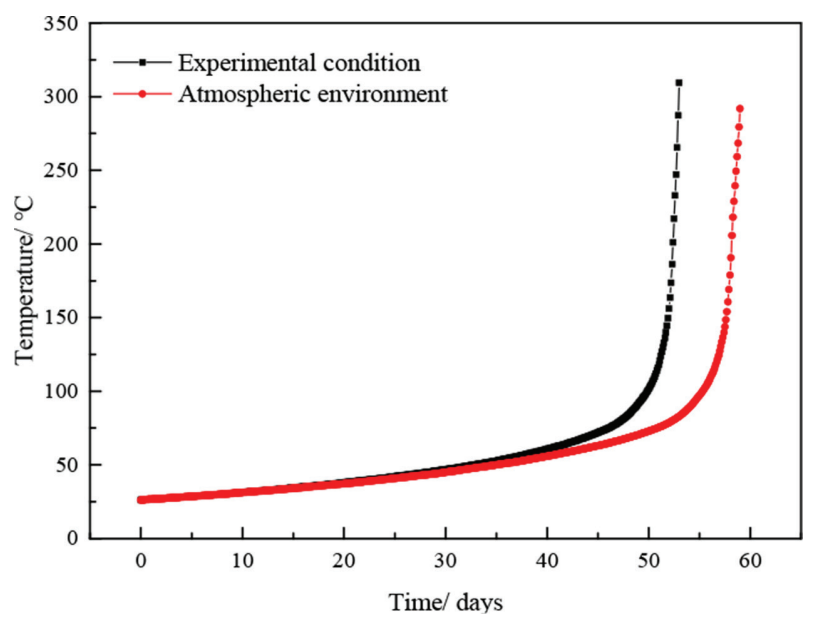

Figure 4: The characteristics of rising coal temperature in various heat dissipation conditions.

was a high demand for the conditions of heat accumulation at the low-temperature stage. In other words, as a result of increased heat exchange, the heat, which came from low-temperature oxidation, was unable to accumulate to make the temperature rise, which reduces the probability of spontaneous combustion of the coal. However, heat dissipation conditions have little impact on the temperature of the fire source at the high temperature stage.

\subsection{Air quantity and direction}

The air quantity was set as $0.5 Q$ and $2 Q$ in gas flow equations respectively; the temperature profiles on various air quantities are shown in Figure 5.
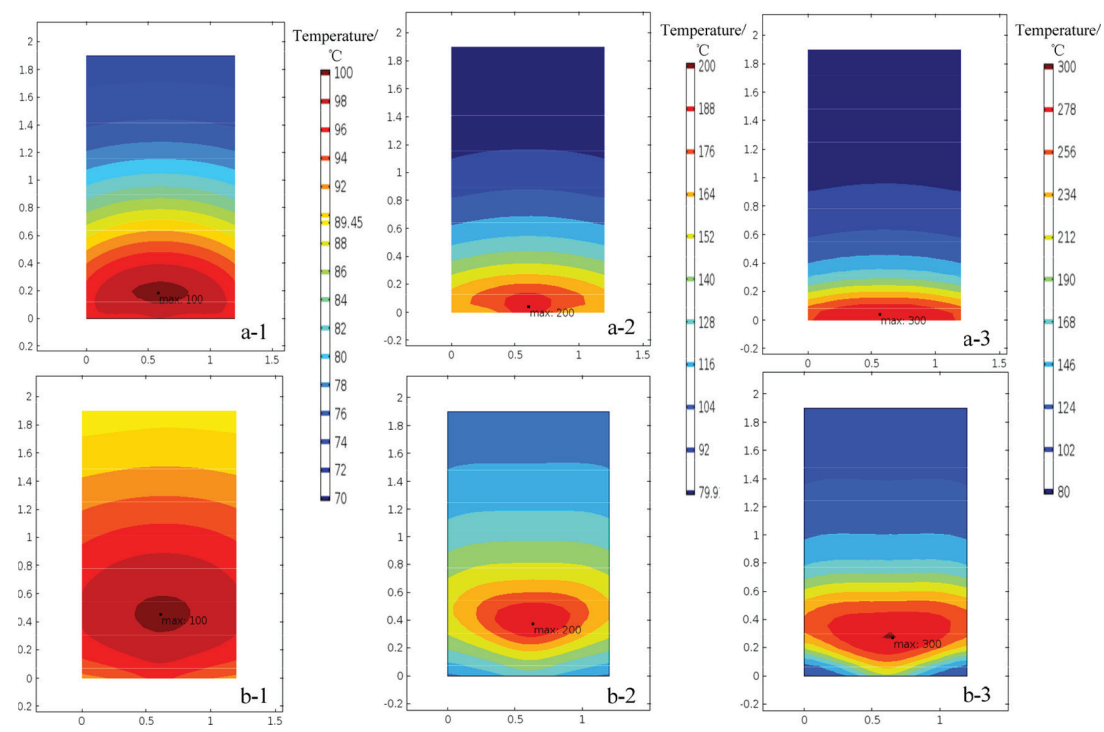

Figure 5: The temperature profile in various air quantities; (a) $0.5 Q$ and (b) $2 Q$. 
Comparing Figure 5 with Figure 3a, at the same temperature stage, changing the air quantity would lead to different fire source locations. In Figure 5a the temperature was about $200^{\circ} \mathrm{C}$ when the high temperature zone gradually moved to the air surface; a similar case was $300^{\circ} \mathrm{C}$ in Figure 3a. This indicated that the greater the air quantity, the higher the temperature when the fire source arrived at the air surface. Such movement of fire source can be explained by oxygen starvation when there is a serious increase in the coal's oxygen consumption.

Meanwhile, as the air quantity increased, the coal temperature gradient decreased, apparently at an identical temperature stage. This means that an enhanced diffusion of air would increase the proportion of fire source zones significantly. The above results illustrated that at various temperature periods, air quantity was another critical factor affecting the fire source position.

To study the relationship between air direction and fire source position, the air inlet position is set at the middle or edge in the boundary conditions respectively. The temperature profile from simulated results can be seen in Figure 6.

Comparing Figure 6 with Figure 3a revealed that, when the air inlet was set at the border, because of less oxygen consumption in the low-temperature oxidation process, the driving force of the airflow may cause a slight shift of the high temperature zone in the reverse direction of the air inlet. With the temperature increase, the air direction did not have a significant impact on fire source distribution. However, above $200^{\circ} \mathrm{C}$, the wind direction evidently promoted the radial diffusion of the fire source zone, and a larger fire area could be seen in Figure 6. The reason for this was that different air inlet positions brought various air leak intensities at the same position and then affected the development of the fire source position.

The fire source temperature in various air quantities during the coal's self-heating is shown in Figure 7a, meanwhile Figure 7b presents the fire source temperature difference for two air directions (middle subtract boundary) at the same time.

Figure 7a showed that the improvement in air quantity within certain limits will accelerate the occurrence of spontaneous combustion. However, a significant increase of air quantity would result in the heat dissipated completely, and then coal temperature remains stable throughout. When the highest temperature was below $70-80^{\circ} \mathrm{C}$, the coal heating rate for various air quantities $(0.5 Q, Q$ and $2 Q)$ was approximately equal. Once above $70-80^{\circ} \mathrm{C}$, the coal's oxygen requirement increased significantly; There was an obvious influence on the heating rate of the fire source if the air quantity changed at this stage. Meanwhile, the temperature difference for various air quantities $(0.5 Q, Q$ and $2 Q)$ increased remarkably. The above phenomenon indicated that the main reasons that improving air quantity will make the spontaneous combustion period shorten were obviously accelerating the high-temperature oxidation reaction of coal, and
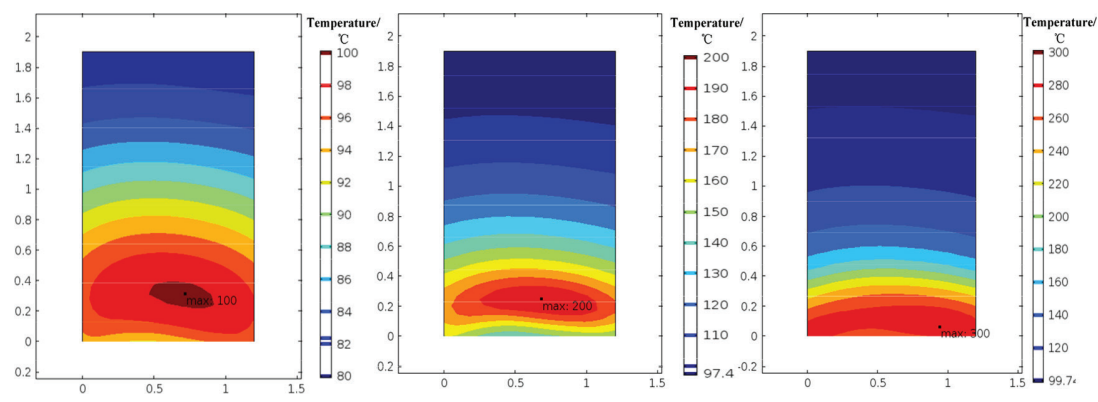

Figure 6: The temperature profile in various air directions. 


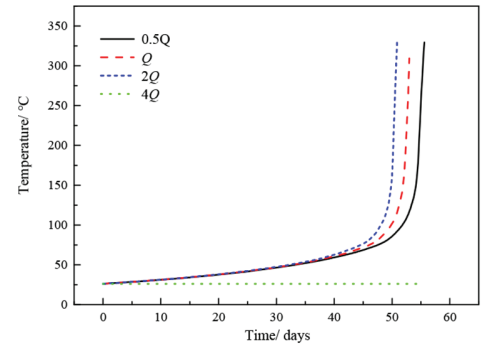

(a)

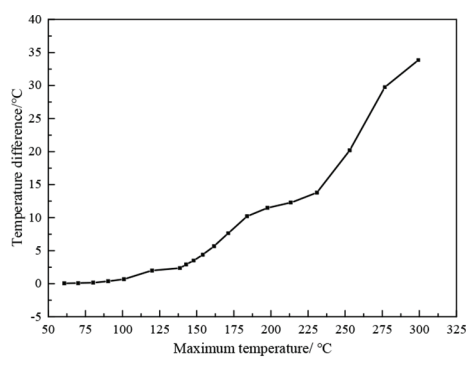

(b)

Figure 7: (a) The characteristics of coal self-heating in various air quantities. (b) Fire source temperature difference for two air directions.

shortening the period from the critical temperature to the combustion temperature. Furthermore, in this study, the optimum air quantity for the coal's self-heating test could be in the range of $2 Q-4 Q$.

Based on experimental conditions, at the same reaction time, the temperature at the middle air inlet position was always higher than at the sides during the computational process. In Figure $7 \mathrm{~b}$, the temperature difference between the middle and the sides was remarkably increased when the fire source temperature was above $100^{\circ} \mathrm{C}$. The above phenomenon indicated not only that the spontaneous combustion period of the middle was shorter than that of the sides, but it also revealed that the middle air inlet will generate more heat in the same period of time in consequence of better contact between the coal particle and oxygen; however, as the result of the total heat from oxidation was small, the influence of the air inlet position on the spontaneous-heating process of the coal was not obvious.

\section{CONCLUSIONS}

A numerical method is presented to reproduce the spontaneous-heating process of coal in a large-scale experimental reactor. This approach has been validated by comparison between simulated and experimental results of the Tianchi coal sample. The model is capable of predicting fire source temperature and position accurately at different temperature stages. Simultaneously, the model solves the problem that it is impossible to change the experimental conditions to perform repetitive experiments for the same coal, and it can also reduce the experimental workload and investigate spontaneous combustion of coal based on a more complex environment.

In addition, the model can be applied to simulate the more probable external environment. Firstly, we can summarize from simulated results that the stronger heat dissipation surroundings and the more air quantity, the higher the temperature when the fire source arrives at the air surface; the greater the temperature gradient, the more obvious fire source zone will focus on the central axis area. Thus, the air direction will have a slight impact on the fire source position during the low temperature oxidation process, and the air leakage conditions have a main influence on the heating rate of the high temperature stage. Finally, the increased heat dissipation will significantly prolong the process of low-temperature oxidation.

These conclusions can help to predict the fire source position and temperature in the actual coal mine environment. 


\section{ACKNOWLEDGEMENT}

The authors are grateful for the support from the Key Projects of the National Natural Science Foundation of China (No. 5113-4019), and the National Natural Science Foundation of China (No. 5140-4195).

\section{REFERENCES}

[1] Song, Z. \& Kuenzer, C., Coal fires in China over the last decade: a comprehensive review. International Journal of Coal Geology, 133, pp. 72-99, 2014. https://doi.org/10.1016/j.coal.2014.09.004

[2] Taraba, B. \& Michalec, Z., Effect of longwall face advance rate on spontaneous heating process in the gob area - CFD modelling. Fuel, 90, pp. 2790-2797, 2011. https://doi.org/10.1016/j.fuel.2011.03.033

[3] Song, Z., Zhu, H., Jia, G. \& He, C., Comprehensive evaluation on self-ignition risks of coal stockpiles using fuzzy AHP approaches. Journal of Loss Prevention in the Process Industries, 32, pp. 78-94, 2014. https://doi.org/10.1016/j.jlp.2014.08.002

[4] Yuan, L. \& Smith, A.C., Experimental study on $\mathrm{CO}$ and $\mathrm{CO}_{2}$ emissions from spontaneous heating of coals at varying temperatures and $\mathrm{O}_{2}$ concentrations. Journal of Loss Prevention in the Process Industries, 26, pp. 1321-1327, 2013. https://doi.org/10.1016/j.jlp.2013.08.002

[5] Qin, Y., Liu, W., Yang, C., Fan, Z., Wang, L. \& Jia, G., Experimental study on oxygen consumption rate of residual coal in goaf. Safety Science, 50, pp. 787-791, 2012. https://doi.org/10.1016/j.ssci.2011.08.033

[6] Arisoy, A. \& Beamish, B., Reaction kinetics of coal oxidation at low temperatures. Fuel, 159, pp. 412-417, 2015. https://doi.org/10.1016/j.fuel.2015.06.054

[7] Taraba, B. \& Pavelek, Z., Investigation of the spontaneous combustion susceptibility of coal using the pulse flow calorimetric method: 25 years of experience. Fuel, 125, pp. 101-105, 2014. https://doi.org/10.1016/j.fuel.2014.02.024

[8] Wang, D., Dou, G., Zhong, X., Xin, H. \& Qin, B., An experimental approach to selecting chemical inhibitors to retard the spontaneous combustion of coal. Fuel, 117, pp. 218-223, 2014. https://doi.org/10.1016/j.fuel.2013.09.070

[9] Deng, J., Xiao, Y., Li, Q., Lu, J. \& Wen, H., Experimental studies of spontaneous combustion and anaerobic cooling of coal. Fuel, 157, pp. 261-269, 2015. https://doi.org/10.1016/j.fuel.2015.04.063

[10] Xia, T., Zhou, F., Liu, J., Kang, J. \& Gao, F., A fully coupled hydro-thermo-mechanical model for the spontaneous combustion of underground coal seams. Fuel, 125, pp. 106115, 2014. https://doi.org/10.1016/j.fuel.2014.02.023

[11] Zhu, H.-q., Song, Z.-y., Tan, B. \& Hao, Y.-z., Numerical investigation and theoretical prediction of self-ignition characteristics of coarse coal stockpiles, Journal of Loss Prevention in the Process Industries, 26, pp. 236-244, 2013. https://doi.org/10.1016/j.jlp.2012.11.006 
[12] Taraba, B., Michalec, Z., Michalcová, V., Blejcha, T., Bojko, M. \& Kozubková, M., CFD simulations of the effect of wind on the spontaneous heating of coal stockpiles. Fuel, 118, pp. 107-112, 2014. https://doi.org/10.1016/j.fuel.2013.10.064

[13] Yuan, L. \& Smith, A. C., CFD modeling of spontaneous heating in a large-scale coal chamber. Journal of Loss Prevention in the Process Industries, 22, pp. 426-433, 2009. https://doi.org/10.1016/j.jlp.2009.02.016

[14] Krajčová, M., Jelemenský, L., Kiša, M. \& Markoš, J., Model predictions on self-heating and prevention of stockpiled coals. Journal of Loss Prevention in the Process Industries, 17, pp. 205-216, 2004.

https://doi.org/10.1016/j.jlp.2004.02.002

[15] Zhu, W. C., Wei, C. H., Liu, J., Qu, H. Y. \& Elsworth, D., A model of coal-gas interaction under variable temperatures. International Journal of Coal Geology, 86, pp. 213-221, 2011. https://doi.org/10.1016/j.coal.2011.01.011

[16] Saboorian-Jooybari, H. \& Pourafshary, P., Significance of non-Darcy flow effect in fractured tight reservoirs. Journal of Natural Gas Science and Engineering, 24, pp. 132-143, 2015. https://doi.org/10.1016/j.jngse.2015.03.003

[17] Wessling, S., Kessels, W., Schmidt, M. \& Krause, U., Investigating dynamic underground coal fires by means of numerical simulation. Geophysical Journal International, 172, pp. 439-454, 2008. https://doi.org/10.1111/j.1365-246x.2007.03568.x

[18] Song, Z.-y., Zhu, H.-q., Tan, B., Wang, H.-y. \& Qin, X.-f., Numerical study on effects of air leakages from abandoned galleries on hill-side coal fires. Fire Safety Journal, 69, pp. 99-110, 2014. https://doi.org/10.1016/j.firesaf.2014.08.011

[19] Zhang, J., Kuenzer, C., Tetzlaff, A., Oertel, D., Zhukov, B. \& Wagner, W., Thermal characteristics of coal fires 2: Results of measurements on simulated coal fires. Journal of Applied Geophysics, 63, pp. 135-147, 2007. https://doi.org/10.1016/j.jappgeo.2007.08.003

[20] Hu. W., Study on Experimental and Numerical Simulation of Coal Self-ignition Process, Xi' an University of Science \& Technology, pp. 40-64, 2003.

[21] Lohrer, C., Schmidt, M. \& Krause, U., A study on the influence of liquid water and water vapour on the self-ignition of lignite coal-experiments and numerical simulations. Journal of Loss Prevention in the Process Industries, 18, pp. 167-177, 2005. https://doi.org/10.1016/j.jlp.2005.03.006

[22] Jianming, W., Investigation and Application of New Techniques and Air-leak Sealants for Coal Spontaneous Combustion Prevention and Extinguishment, Tai yuan University of Technology, pp. 44-50, 2008. 